\title{
METODOLOGIA DO ENSINO DA GINÁSTICA: NOVOS OLHARES, NOVAS PERSPECTIVAS
}

\author{
LuCIANA MarCassa*
}

\section{RESUMO}

Este artigo busca sistematizar uma proposta metodológica para o ensino da Ginástica escolar e comunitária, que vem sendo construída a partir de experiências realizadas junto aos projetos de ensino, pesquisa e extensão vinculados ao Grupo de Estudo, Pesquisa e Experimentação em Ginástica (GEPEGIN), da Faculdade de Educação Física da UFG. A proposta indica alguns princípios, conteúdos e estratégias de ação que possam contribuir para o processo de formação humana crítica, na tentativa de apontar uma nova perspectiva para o ensino, a prática e o conhecimento da Ginástica.

PALAVRAS-CHAVE: metodologia da ginástica - formação humana-linguagem corporal.

\section{INTRODUÇÃO}

Sem dúvida alguma, as diferentes e crescentes propostas que vêm sendo construídas nos últimos vinte anos no campo da Educação Física trouxeram importantes contribuições para o constante repensar sobre a prática pedagógica, entendendo que esta deve vir acompanhada da teoria da Educação, que lhe sustenta e que lhe dá sentido. Entretanto, não obstante os avanços contados neste âmbito, ainda sentimos a necessidade de discutir e aprofundar o debate acerca dos seus conteúdos específicos, sobre os temas da cultura corporal, cuja manifestação transcende ao universo da escola, mas estabelece com esta vínculos determinantes.

* Mestre em Educação pela Faculdade de Educação da Universidade Federal de Goiás, Professora da Faculdade de Educação Física da Universidade Federal de Goiás, Pesquisadora do Colégio Brasileiro de Ciências do Esporte e Coordenadora do Grupo de Estudo, Pesquisa e Experimentação em Ginástica da Faculdade de Educação Física da Universidade Federal de Goiás. 
Queremos aqui refletir sobre a Ginástica, visto ser este um importante conteúdo da Educação Física escolar e expressivo componente da cultura corporal. Além disso, a abordagem deste tema justifica-se também porque, contraditoriamente, sua concepção e manifestação têm empobrecido muito na atualidade ${ }^{1}$, embora seja hoje uma das atividades mais procuradas, como também uma das mais diversificadas, com visível proliferação de modalidades, visões e métodos de ensino, variadas inserções, origens, finalidades e possibilidades de acesso e experimentação.

Nesse sentido, nossa preocupação é apontar pistas para o trato pedagógico da Ginástica na escola, mas também lançar novos olhares que permitam recolocá-la sob outras perspectivas conceituais e práticas, possibilitando a ampliação das experiências e dos saberes corporais sobre e a partir desta manifestação, nos diversos ambientes educacionais em que ela pode se fazer presente. Para tanto, buscamos a compreensão da Ginástica como uma linguagem corporal e, como tal, veículo e objeto de comunicação. E nesta procura, encontramos na experimentação e registro de diferentes práticas educativas envolvendo o movimento expressivo, juntamente com o estudo da Ginástica Geral, interessantes respostas para a elaboração e sistematização de uma proposta metodológica que intenta avançar, também, no conhecimento da corporalidade e da gestualidade essenciais à linguagem gímnica.

Nosso ponto de partida nesta proposta situa o corpo e as práticas corporais no centro do processo de ensino e aprendizagem como elementos tanto constituídos pela produção cultural que os envolve, quanto constitutivos da ação educativa presente na vida cotidiana, na mediação e construção de valores, saberes, comportamentos e práticas que eles se revertem/retornam na medida mesma em que são produzidos seus significados. É o que sugere Soares (2001, p. 110): “Os corpos são educados por toda realidade que os circunda, por todas as coisas com as quais convivem, pelas relações que estabelecem em espaços definidos e delimitados por atos de conhecimento".

Estamos convencidos, como Gonçalves (1994), de que o corpo é um meio de comunicação empática com o mundo, participante ativo dos processos de sociabilidade, da produção material e simbólica e das experiências culturais. Ora, as práticas corporais são também partícipes desse movimento, já que os gestos, as posturas e os movimentos contêm sentidos e significados que nos educam constantemente, bem como símbolos e signos de linguagem que 
dizem muito sobre a nossa formação cultural e revelam aspectos da dimensão social e subjetiva que fundamentam o nosso modo de ser, viver e compreender a realidade. Recorrendo novamente a Soares:

O gesto contém forças reveladoras de um poder de persuasão impossível para a palavra. Ele põe em jogo todos os sentidos não só de quem o executa, mas também de quem o observa. Os gestos permitem um reconhecimento da pessoa em suas dimensões moral e psicológica, pois conforme Revel, sendo signos, podem organizar-se numa linguagem (2001, p. 111-112).

Quando nos referimos ao corpo e às práticas corporais, estamos falando de uma linguagem muda, porém carregada de sons, imagens, palavras, cores, odores, sensações, percepções, valores, conhecimentos, sentidos e significados. Estamos pensando um tipo de gramática que emana do corpo, uma narrativa composta de movimentos, gestos, posturas e expressões não verbais que, articuladas e seqüenciadas, configuram o que podemos chamar de linguagem corporal, intimamente vinculada ao corpo e às suas possibilidades de comunicação.

Em nossa perspectiva, a linguagem corporal é o objeto da Educação Física que, na escola, tem por objetivo:

[...] desenvolver uma reflexão sobre o acervo de formas de representação do mundo que o homem tem produzido no decorrer da história, exteriorizadas pela expressão corporal: jogos, danças, lutas, exercícios ginásticos, esporte, malabarismo, contorcionismo, mímica e outros, que podem ser identificados como formas de representação simbólica de realidades vividas pelo homem, historicamente criadas e culturalmente desenvolvidas (COLETIVO DEAUTORES, 1992, p. 38).

É assim que pensamos a Ginástica no contexto da Educação Física escolar, isto é, como um tema que se insere na chamada cultura corporal e que, portanto, deve ser tratado, experimentado, problematizado, conhecido e transformado. Entre outros temas como a dança, os jogos, as lutas, a capoeira e o esporte, a Ginástica manifesta-se de modo articulado com as aspirações, projetos e relações existentes em nossa sociedade e, em qualquer circunstância, é uma forma de expressão não verbal de valores, idéias, concepções, saberes e práticas sociais. Para Coletivo de Autores (1992), a expressão corporal é uma linguagem, um conhecimento universal, 
patrimônio da humanidade e, como tal, precisa ser transmitido e assimilado pelos alunos na escola, pois a sua ausência impede que o homem e a realidade sejam compreendidos em sua totalidade.

No corpo e nas suas manifestações são gravadas as impressões da cultura e, assim, como meios de inscrição e revelação do processo social e educativo de uma dada sociedade, o corpo, os gestos, os movimentos e as práticas corporais se tornam um campo fértil através do qual podemos conhecer e intervir sobre a realidade. Desse modo, a corporalidade é uma dimensão humana que precisa ser considerada quando da elaboração de uma proposta de educação que se pretenda crítica, criativa e integral, em que todos os domínios e capacidades humanas sejam promovidos e ampliados.

Parece-nos, entretanto, que somente uma formação omnilateral é capaz de dar conta da totalidade do ser humano e de suas expressões, relações, produções e práticas. O conceito de omnilateralidade, cunhado primeiramente por Marx e depois por Gramsci, retoma a idéia de homem integral, já utilizada por Aristóteles, mas para este último, a educação é o desenvolvimento de potências ou potencialidades humanas preexistentes no homem, bastando apenas atualizá-las, colocá-las em ato. Para este pensamento, de acordo com uma concepção essencialista de homem, é esta a tarefa da educação: desenvolver no homem habilidades e competências inatas referentes a uma idéia absoluta, habitante numa realidade metafísica chamada de "Mundo das Idéias".

Para Marx e Gramsci, no entanto, a ominilateralidade não é o desenvolvimento de potencialidades humanas inatas. É a criação dessas potencialidades pelo próprio homem, na prática social, no "Mundo do Trabalho". Nessa perspectiva, a educação está vinculada à produção social total, bem como a todas as dimensões da existência e da ação humanas. E considerando a luta e a desigualdade instalada numa sociedade de classes, tal proposta objetiva oportunizar a todos o acesso aos bens culturais produzidos pela humanidade, qualificando as relações sociais e intensificando as trocas e experiências que ampliam/enriquecem a forma de ler, de compreender e de viver a realidade. A formação omnilateral deseja, então, a criação e o desenvolvimento das capacidades humanas em si mesmas e, ancorada num compromisso político, deve "instrumentalizar" o homem para que possa enfrentar as mudanças, conflitos, contradições e exigências que o mundo do trabalho lhe impõe, 
superando, assim, as condições de opressão e dominação existentes. Enfim, a omnilateralidade é:

[...] o chegar histórico do homem a uma totalidade de capacidades e, ao mesmo tempo de gozo (desfrute, fruição), em que se deve considerar sobretudo o usufruir os bens espirituais, além dos materiais de que o trabalhador tem estado excluído em consequiência da divisão do trabalho (MANACORDA, apud GADOTTI, 1984).

Dentro desta visão de educação, a Educação Física pode se inserir, pelo menos, de duas maneiras. Primeiro, colocando à disposição de todos os grupos e classes sociais os conhecimentos, experiências, bens simbólicos e materiais que, ligados ao corpo e à cultura corporal, foram produzidos historicamente pela humanidade, postura que pode colaborar no processo de democratização da cultura e das riquezas. E em segundo lugar, pela superação das concepções e práticas relacionadas ao corpo e às suas manifestações, na direção da construção de outros alicerces em que as expressões, produções e relações humanas se ampliem e se (re) signifiquem, fornecendo novas referências para os demais campos de conhecimento, bem como para toda a sociedade.

Mas, como contribuir efetivamente para ampliarmos nossa compreensão sobre o corpo e as atividades corporais, apontando novas perspectivas para o redimensionamento dos valores, ações, interesses e possibilidades de nos relacionarmos com eles e de nos comunicarmos com o mundo, permitindo, também, experimentar novas e diferentes formas de convivência e sociabilidade?

Essa tem sido a questão que nos orienta quando da elaboração de uma Metodologia da Ginástica. Desse modo, com base no princípio de que a corporalidade é uma dimensão construída culturalmente e que constitui todo e qualquer processo educativo, acreditamos que o conhecimento e a experimentação da Ginástica como linguagem pode ser uma das possibilidades para a ascensão a uma formação omnilateral. Formação esta que, como já dissemos, pressupõe o desenvolvimento humano em todos os seus domínios: moral, afetivo, corporal, cognitivo, ético, estético, político, etc. Concebendo-a como uma forma de expressão e comunicação - o que se contrapõe à prática da Ginástica no mundo do esporte e do fitness -, temos pensado a Ginástica como uma manifestação pertencente ao universo das linguagens artísticas contemporâneas. 
Ao lado da dança, do circo novo, das performances, da música, das artes cênicas e visuais, a Ginástica se apresenta hoje como um campo vasto, rico em conteúdos, variado em formações plásticas e quase inesgotável em possibilidades de expressão, criação e transformação, pois é composto por um denso registro de saberes que permitem ampliar, interagir e mesclar a Ginástica a outras expressões, tendências e sistematizações, e também identificá-la e caracterizá-la como uma prática específica e singular. É recuperando e fortalecendo a sua identidade e seus significados historicamente construídos que procuramos conceber a Ginástica.

Queremos afirmar com isso que a Ginástica não pode ser compreendida se não considerarmos alguns aspectos: seu conteúdo, ou seja, os movimentos gímnicos, também chamados de fundamentos básicos da ginástica, que compreendem um rol de ações, posturas, movimentos e gestos que historicamente foram associados, combinados e sistematizados em torno dos métodos ginásticos e lições de educação física e que, mais tarde vieram a se desdobrar nos elementos específicos das modalidades que conhecemos hoje como a Ginástica Artística, Rítmica, Natural ${ }^{3}$, Aeróbica, Acrobática, Calistênica, etc; sua forma, isto é, os movimentos e sequiências ginásticas possuem uma estética própria, uma configuração plástica, um conjunto de posturas e gestos que podem ser traduzidos e representados pelos signos da retidão e verticalidade (SOARES, 1998).

Tudo isso supõe, portanto, que consideremos sua história, porque todos os saberes relativos ao corpo e a este conjunto sistematizado de exercícios corporais foram construídos historicamente, o que implica que seus sentidos e seus significados só podem ser visualizados e interpretados na e através da história. Importante também é seu objetivo, que representa a intencionalidade da proposta pedagógica e o direcionamento a ser dado, na prática, para que as finalidades educativas sejam alcançadas; e por fim sua orientação metodológica e as estratégias através das quais a Ginástica pode ser praticada, conhecida, refletida e recriada.

Fundamentando-se nestes princípios, temos defendido a proposta da Ginástica Geral como aquela capaz de garantir a identidade da ginástica, mantendo seu conteúdo e forma, mas transcendendo aos aspectos meramente técnicos que predominam nas concepções mais tradicionais. Tal proposta amplia o universo dos exercícios e atividades ginásticas para uma compreensão de que o movimento gímnico é também expressivo, e de que a expressão é uma possibilidade, não só, de comunicação interna, 
referente ao conhecimento e à percepção que os sujeitos têm das suas próprias qualidades corporais, mas também de comunicação e contato entre as pessoas que partilham ou não do mesmo meio social ou de uma mesma sociedade e cultura.

A Ginástica Geral, que se apresenta como uma leitura contemporânea da Ginástica, abarca o conjunto das várias modalidades ginásticas, bem como elementos da dança, do circo, da capoeira, dos jogos, das lutas, enfim, das diversas manifestações da cultura corporal que, todavia, ao serem apropriadas e interpretadas pelos movimentos ginásticos, são transformadas e incorporadas à linguagem gímnica. Queremos dizer com isso que o eixo fundamental da Ginástica Geral continua sendo a Ginástica, a qual, embora possa dialogar e interagir com outras práticas e outros elementos da cultura corporal, contém uma narrativa própria, constituída pelos signos e caracteres (conteúdo, forma, história, objetivos e orientação metodológica) que configuram e materializam a seu tipo de linguagem.

Isto significa que a GG precisa conquistar a sua identidade e buscar a sua amplitude e diversidade tendo como base a ginástica, compreendida como uma prática corporal que, marcadamente desde o início do século XIX, sofreu um processo intensivo de sistematização em diferentes países europeus, o qual foi responsável pela configuração de um conjunto de elementos característicos que constituem a ginástica - os gestos gímnicos -, que, apesar da multiplicidade de enfoques e da diversidade de manifestações gímnicas existentes na atualidade, podem ser subdivididos em: elementos corporais, exercícios acrobáticos e exercícios de condicionamento físico (sem, com e em aparelhos). Nesse sentido, o processo de sistematização e codificação da ginástica permite-nos diferenciar uma manifestação gímnica de outras formas de manifestação, ou seja, distinguir a ginástica de outros temas da cultura corporal. Daí podermos perceber as diferenças entre um salto característico da ginástica artística, um salto característico do balé clássico ou um salto característico do voleibol. O salto, como gesto, ganha significado no contexto da atividade que o caracteriza (AYOUB, 2003, p. 73-74).

Eliana Ayoub é uma das autoras que também se preocupam com a adequada assimilação da Ginástica Geral pelo campo da Educação Física, ou seja, que a ginástica seja pensada e experimentada em sua inteireza, inclusive na escola. Em seus textos, chama a atenção para que esse esforço 
de diferenciação da Ginástica de outras práticas corporais não signifique compartimentalizar os conhecimentos, uma vez que nenhuma prática corporal pode ser compreendida de forma isolada, mas na totalidade da cultura corporal. E apesar das influências recíprocas que as diferentes manifestações corporais exercem e exerceram umas sobre as outras (a relação entre a dança, a ginástica e o circo não nos deixa mentir), parece importante concordar com ela no que diz respeito à necessária distinção entre tais práticas, sem, contudo, apartá-las absolutamente.

Assim, segundo Ayoub (2003), a Ginástica Geral carrega consigo alguns traços que merecem ser destacados. Sem finalidade competitiva, está situada num plano diferente das modalidades competitivas, com abertura para o divertimento, o prazer, a simplicidade de movimentos, a participação irrestrita; seu principal alvo é o sujeito que a pratica e a meta é a integração entre as pessoas e grupos, desenvolvendo a criatividade e o interesse pela ginástica; a liberdade de expressão, a criação e o componente lúdico são elementos marcantes desta prática; ela é ampla, diversificada e não tem regras rígidas preestabelecidas, o que implica em respeito aos limites e possibilidades de cada um; os festivais são sua principal forma de manifestação, o que não significa desconsiderar o processo em detrimento do produto final, mas sim valorizar a expressão artística que se vincula à composição coreográfica, à apresentação e ao espetáculo.

Além disso, a GG prevê a confecção, a exploração e o desenvolvimento de ações corporais/gímnicas com materiais alternativos - porém não substitutivos aos equipamentos oficiais - como bastões, cordas grandes, jornal, elástico, sombrinhas, bambus, toalhas de rosto, lençol, caixas de refrigerante, travesseiros, etc, que são manipulados de acordo com os fundamentos específicos da Ginástica e com outros movimentos que podem ser criados em função das propriedades internas do material, o qual também se torna um componente cênico do processo de composição coreográfica.

Quanto a estes aspectos, da exploração de materiais e da composição coreográfica, cabe salientar que deve ser experimentado individual e coletivamente, por meio da pesquisa, da criação e da expressão de movimentos que resgatam tanto as referências individuais como as coletivamente partilhadas. Chamamos este momento de revelação e reconstrução das narrativas corporais e seu propósito é refletir, identificar, compreender e superar os padrões, as práticas e a cultura corporal internalizadas ${ }^{4}$, recuperando as experiências mais significativas e os saberes corporais prévios, 
numa tentativa de revisão da história do corpo em movimento, tanto no plano da individualidade como no plano da economia, da sociedade e da cultura mais amplas. Esse momento é indispensável nesta proposta, uma vez que os limites, preconceitos e dispositivos de controle que nos são impostos cotidianamente impedem ou, pelo menos, dificultam um contato e um conhecimento mais apurado de nossas qualidades corporais. Além disso, os saberes que envolvem o domínio da corporalidade e das características inerentes ao corpo e ao movimento de cada um, são cruciais na construção da autonomia dos sujeitos, de novas descobertas sobre si mesmo e de criativos desfechos em expressão corporal.

Em nossa proposta, o processo de criação é a chave da ação pedagógica na medida em que se realiza a partir das referências anteriores que os indivíduos e grupos trazem para o contexto da aula, mas por meio de um envolvimento coletivo no trato do conteúdo e da forma coreográfica a ser alcançada. Esse processo é orientado pela tematização, que constitui um momento ímpar de problematização e teorização de situações vividas ou dados concretos que compõem a realidade na qual estamos inseridos, conduzindo à leitura, à interpretação e ao conhecimento do mundo que nos cerca. O momento da tematização deve ser norteado por uma pesquisa ou investigação que permita aos alunos aprofundar os saberes que já possuem sobre determinada questão para além das informações que trazem consigo, das imagens primeiras, ou dos dados que estão disponíveis no plano das aparências. Um outro momento deste mesmo processo diz respeito à seleção dos conhecimentos obtidos e à codificação dos mesmos em signos de linguagem, ou seja, a sua transformação em movimentos gímnico-expressivos. Depois, tratase de combinar, seqüenciar e contextualizar as ações, gestos e posturas em um "texto", ou seja, na coreografia temática que dará sentido ao conteúdo a ser comunicado. Essa possibilidade de expressar, através do corpo e da linguagem da ginástica, os dados da realidade que nos cerca torna-se, então, um caminho interessante para conhecermos melhor a nós mesmos, a nossa situação real e atual, como para a compreensão e interpretação da história vivida ou projetada.

Sobre a tematização, é importante dizer ainda que são variados os temas que podem ser tratados e investigados como eixos articuladores da produção e apropriação de saberes, da interpretação crítica, da significação e da expressão corporal. As experiências que temos realizado 
neste âmbito nos indicam que as composições podem falar sobre questões que se articulam ao próprio universo da ginástica, como seus conteúdos, fundamentos e variações, bem como de outros elementos que habitam a realidade material ou simbólica, definidos a partir de fatos ou circunstâncias específicas, ou ainda do contexto histórico e cultural mais amplo, que ao serem trazidos para o âmbito da coreografia, ganham um tratamento peculiar a partir da linguagem dos movimentos ginásticos.

Esse processo da composição coreográfica que resulta numa performance temática, ao expressar e comunicar conteúdos intrínsecos à história da vida de cada um e à dinâmica cultural que perpassa toda a sociedade, configura-se numa linguagem que, inclusive, possui quase as mesmas estruturas da linguagem escrita. Costumamos dizer que a coreografia é como um texto. E se para um texto escrito é necessário ter conteúdo, narrativa, coerência interna, situalização, intencionalidade, coesão, contextualização, intertextualidade, etc, na linguagem corporal gímnica alguns desses elementos também estão presentes. O conteúdo é o tema a ser problematizado; a narrativa possui uma lógica e se manifesta por meio de movimentos, gestos, ações motoras, posturas, expressões que, por sua vez, são como as palavras, signos de linguagem; pela investigação temática e pesquisa de movimentos buscamos a coerência interna, que também se traduz pela harmonia e sincronização na execução das formações e figuras adotadas na composição; já a contextualização e a intencionalidade indicam de onde a reflexão/ação partiu e aonde ela quer chegar, embora, como toda obra de arte, a coreografia final possa ser interpretada de acordo com os recursos e com a visão social de mundo que os espectadores possuem. Enfim, acreditamos ser este o momento de síntese do trabalho, o qual pode levar desde uma única aula, até meses ou anos de dedicação, dependendo do objetivo a ser conquistado.

Assim, a presença da ginástica no programa [de Educação Física] se faz legítima na medida em que permite ao aluno a interpretação subjetiva das atividades ginásticas, através de um espaço amplo de liberdade para vivenciar as próprias ações corporais. [...] A abordagem problematizadora, anteriormente exemplificada, assegura a globalidade das ações das crianças e a compreensão do sentido/significado da própria prática (COLETIVODEAUTORES, 1992, p. 77-79). 
Quanto à dimensão propriamente artística da proposta, temos defendido que a criação, expressão, interpretação de signos gestuais, pesquisa de movimentos e composição de coreografias temáticas na Ginástica Geral culminam numa mescla de linguagens. Acreditamos que a linguagem corporal gímnica prescinde, se funde e se articula às linguagens artísticas como a música (na produção de sons através do corpo e da construção de instrumentos musicais, ou ainda no trabalho permanente com ritmo), as artes plásticas ou visuais (na criação de cenários, figurinos e, especialmente, na elaboração de uma linguagem/imagem visual revelada na coreografia), e das artes cênicas, já que, através da tematização, da investigação teórica e da pesquisa de movimentos, realiza-se, constantemente, interpretação e representação de personagens, idéias e sentimentos, comportamentos etc. (MARCASSA, 2002).

Para que tudo isso se torne possível, é necessário, porém, implementar uma alternativa didática e uma orientação metodológica em que prevaleça o envolvimento coletivo na discussão e tratamento dos conflitos e situações que decorrem da difícil tarefa de criar, aprender e se expressar em conjunto, mas respeitando os limites e as possibilidades de cada um. Comungamos, então, da concepção de ensino respaldada pelas Aulas Abertas à Experiência, cujo objetivo é a participação coletiva na direção do processo ensino-aprendizagem; ao passo que os sujeitos vão reorganizando suas referências em relação aos conhecimentos do corpo, da Ginástica e da própria realidade, a construção da autonomia, da capacidade de crítica e de comunicação entre eles vai também se ampliando e se enriquecendo.

As concepções de ensino são abertas quando os alunos participam das decisões em relação aos objetivos, conteúdos e âmbitos de transmissão dentro deste complexo de decisão. O grau de abertura depende do grau de possibilidade de co-decisão. As possibilidades de decisão dos alunos são determinadas cada vez mais pela decisão prévia do professor (HILDEBRANDT, 1986, p. 15).

No que concerne aos objetivos da proposta, procuramos incentivar a construção de um maior grau de autonomia e de interferência dos sujeitos participantes nas decisões e ações a serem desencadeadas pelo coletivo, promovendo uma reflexão sobre a cultura corporal em seus nexos com a realidade social mais ampla, o que se dá de maneira até 
bastante verticalizada e complexa, chegando os grupos a fazerem coreografias inteiras sobre a sua interpretação dos problemas concretos vividos pela sociedade brasileira, por exemplo. Por meio de situações lúdicas, jogos dramáticos, pesquisa de movimentos, oficinas de expressão corporal e exploração de sons e materiais, busca-se a experimentação das ações e gestos gímnicos, como os saltos, giros, rolamentos, inversões, formas de equilíbrio, acrobacias, suspensões, apoios, lançamentos, manipulação de objetos outros, almejando a maior diversidade possível das experiências, mas respeitando as dificuldades postas e o alcance manifestado pelo grupo. Assim, diferentes possibilidades de movimento vão, aos poucos, formando e complexificando o vocabulário corporal de maneira que o conhecimento sobre o corpo, a Ginástica e a linguagem corporal parece ser construído espontaneamente.

Entretanto, não são deixados de lado, em nenhum momento, conforme sugere Snyders (1988), o compromisso com a diretividade, o sistemático, o difícil, o obrigatório e a necessária organização do saber que, neste caso, contém um duplo caráter. Segundo Bracht (1997, p. 18), é um saber que se traduz por um "saber-fazer" e um "saber sobre" esse fazer corporal, cujas relações perpassam a tecem o universo da Ginástica e todas as suas vinculações, ramificações, contradições e ambigüidades. Queremos dizer com isso que existem dimensões da aprendizagem relacionadas à linguagem corporal que somente são passíveis de serem propiciadas pela execução de gestos, pelo ato de movimentar-se e que, portanto, dificilmente podem ser descritas, explicadas ou racionalizadas. É assim que, retomando Bracht (1997), podemos falar em uma tentativa de ampliação do conceito de linguagem corporal para aquele que não é nem só pensamento, nem só movimento, mas movimento-pensamento.

Nesse sentido, os fundamentos básicos da Ginástica Geral não são de forma alguma desprezados, mas sim considerados no sentido dado por Mauss (1974) às técnicas corporais 5 . Entretanto, nenhum movimento é trabalhado de forma isolada ou descontextualizado, embora tenhamos, sim, uma preocupação com a estética do movimento gímnico, compreendendo que esta é uma qualidade, sempre superior e muito diversificada, que pode ser adquirida e atribuída ao gesto com o tempo, o conhecimento e a experiência. Como o treinamento não é o objetivo central da proposta, a prática e a técnica são experimentadas como possibilidades de melhorar e ampliar a qualidade e a harmonia dos movimentos e da criação coreográfica. 
O processo de comunicação intra e interpessoal se dá constantemente por meio de uma variedade enorme de atividades expressivas que envolvem, então, ações de resgate e reconstrução dos saberes prévios, vivência dos fundamentos e aparelhos oficiais da ginástica, pesquisa e exploração de movimentos com base nas referências individuais e coletivas, criação e expressão de seqüências e composições temáticas, oficinas de construção de materiais, instrumentos musicais, cenário e figurino, dramatização e significação de narrativas corporais a serem representadas pela linguagem da Ginástica.

Esta proposta é capaz de promover um conhecimento aguçado sobre o corpo, suas qualidades e as manifestações gímnicas, bem como em termos de expressão cênica e capacidade de comunicação dos conteúdos desejados. Ademais, acreditamos que as dificuldades, contradições e limites presentes na ação pedagógica são, aos poucos, superados, na medida em que os pré-conceitos existentes entram em confronto com as novas concepções de corpo, homem, mundo e sociedade construídos pela prática da Ginástica e pelas discussões que ocorrem no desenvolvimento das atividades.

Assim como temos procurado fazer com a Ginástica, a Educação Física comprometida com uma formação crítica necessita da construção e da sistematização qualificada de novas metodologias envolvendo outros elementos da cultura corporal, pois um projeto de educação ampliada, omnilateral, requer uma preocupação com todos os domínios do ser humano, inclusive o corporal. É nesta perspectiva que apostamos e inserimos a proposta apresentada, objetivando, com base em Saviani (1996, p. 38), "tornar o homem cada vez mais capaz de conhecer os elementos de sua situação para intervir nela transformando-a, no sentido de uma ampliação da liberdade, da comunicação e da colaboração entre os homens". É para este projeto de sociedade que procuramos dar a nossa contribuição, colaborando para a formação humana crítica e transformadora.

Gym teaching methodology: new approaches, new perspectives

\begin{abstract}
This article aims at systematizing a methodological approach for the teaching of gym in schools and communities, which is being built from the experiences held with teaching, research, and extension (community-bound) projects linked to GEPEGIN - the Study, Research, and Gym Experimentation Group, from the Physical Education Department
\end{abstract}


at UFG - the Federal University of Goias. This approach indicates some principles, contents, and strategies for action that might contribute to the process of human education in a critical way, in an attempt to point towards a new perspective for the teaching, the practice, and the knowledge of Gymnastics.

KEY-WORDS: gymnastics methodology - human education - body language.

Metodología de enseñanza de la gimnasia: Nuevos horizontes, nuevas perspectivas

\section{RESUMEN}

Este artículo busca sistematizar una propuesta metodológica para la enseñanza de la Gimnasia escolar y comunitaria, que viene siendo construida a partir de experiencias realizadas junto a los proyectos de enseñanza, pesquisa y extensión vinculados al Grupo de Estudio, Pesquisa y Experimentación en Gimnasia (GEPEGIN), de la Facultad de Educación Física de la UFG. La propuesta indica algunos principios, contenidos y estrategias de acción que puedan contribuir para el proceso de formación humana crítica, intenta señalar una nueva perspectiva para la enseñanza, la práctica y el conocimiento de la Gimnasia.

PALABRAS-CLAVE: metodología de la gimnasia-formación humana-lenguaje corporal.

\section{NOTAS}

1 O empobrecimento da ginástica refere-se aqui aos modismos que reduzem os saberes e a vivência da ginástica a mera atividade física, cujo objetivo é o alcance de um padrão corporal disseminado pela Indústria Cultural, presente na mídia, nas academias de ginástica e fitness, no mercado da moda, dos cosméticos e da medicina estética. Tais modismos abarcam e suprimem tanto as possibilidades de prática da ginástica, como também as idéias, os valores e os comportamentos que a ela se vinculam.

2 A instrumentalização é aqui tomada em sua dimensão política, como uma ferramenta para que a classe trabalhadora tenha acesso aos bens materiais e simbólicos produzidos pela humanidade, o que lhe permite acessar os conhecimentos e as técnicas necessárias para a superação da sua condição de exploração e dominação. É também considerada conforme Snyders (1984) quando problematiza as pedagogias não diretivas.

3 A Ginástica Natural é uma modalidade que surgiu no século XIX compondo o chamado "Movimento Ginástico Europeu”. Foi originalmente sistematizado por Georges Hébert e se caracteriza pela execução de uma sequiência de movimentos ou ações motoras como 
andar, correr, marchar, suspender, carregar, lançar, saltar, etc; movimentos estes passíveis de serem observados no cotidiano das pessoas. Por isso, não se confunde com aquela modalidade de mesmo nome que hoje vem se afirmando nas academias de ginástica, cuja proposta é a execução de movimentos que imitam os animais. Para maiores informações, consultar Marinho (s/d) e Soares (1994, 2003).

4 Em nossas pesquisas e experiências, quando solicitamos a recuperação das aprendizagens corporais prévias e discutimos a origem, o sentido e o contexto em que essas práticas e saberes foram gerados, freqüentemente o que nos aparece são referências fortemente marcadas pela cultura esportiva, inclusive no domínio da ginástica.

5 Consideramos aqui a noção de técnicas corporais como um constructo histórico, tradicional e eficaz, de alguma forma ordenado conforme a educação, os valores, as idéias e os simbolismos que compõem uma determinada sociedade e cultura.

\section{REFERÊNCIAS}

AYOUB, Eliana. Ginástica geral e Educação Física escolar. Campinas: Unicamp, 2003.

BRACHT, Valter. Educação Física: conhecimento e especificidade. In: SOUSA, Eustáquia Salvadora, VAGO, Tarcísio Mauro (Orgs.). Trilhas e partilhas. Belo Horizonte: Cultura, 1997, p.13-23.

COLETIVO DE AUTORES. Metodologia do ensino da Educação Física. São Paulo: Cortez, 1992.

GADOTTI, Moacir. Concepção dialética da educação. 3. ed. São Paulo: Cortez: Autores Associados, 1984.

GONÇALVES, Maria Augusta Salin. Sentir, pensar, agir: corporeidade e educação. Campinas: Papirus, 1994.

HILDEBRANDT, Reiner. Concepções abertas no ensino da Educação Física. Rio de Janeiro: Ao Livro Técnico, 1986.

MARCASSA, Luciana. A Ginástica escolar no currículo da FEF/UFG: uma trajetória possível. VII Semana Científica da Faculdade de Educação Física da UFG, Anais ... Jataí, 2002. 
MARINHO, Inezil Penna. Sistemas e métodos de Educação Física. 4. ed. São Paulo: Cia Brasil, [S.d.].

MAUSS, Marcel. As técnicas corporais. In: Sociologia e antropologia. São Paulo, EDUSP, 1974, p.209-221.

SAVIANI, Dermeval. Educação: do senso comum à consciência filosófica. 12. ed. Campinas: Autores Associados, 1996.

SOARES, Carmen. Educação Física: raízes européias e Brasil. Campinas: Autores Associados, 1994.

Imagens da educação no corpo. Campinas: Autores Associados, 1998.

Corpo, conhecimento e educação: notas esparsas. In: SOARES, Carmen (Org.). Corpo e história. Campinas: Autores Associados, 2001.

SOARES, Carmen. Georges Hébert e o método natural: nova sensibilidade, nova educação do corpo. Revista Brasileira de Ciências do Esporte, v. 25, n. 1, p.21-39, Campinas: CBCE: Autores Associados, setembro, 2003.

SNYDERS, Georges. As pedagogias não diretivas. In: SNYDERS, G. LÉON, A; GRACIO, R. Correntes actuais da pedagogia. Lisboa: Livros Horizonte, 1984, p.14-38.

A alegria na escola. São Paulo: Manole, 1988.

Recebido: 30 de abril 2004

Aprovado: junho de 2004

Endereço para correspondência

Faculdade de Educação Física,

Universidade Federal de Goiás, Campus II

Setor Samambaia - Goiânia - Goiás

CEP 74001-970.

E-mail: lu.marcassa@uol.com.br 